\title{
Mixed Methods: Expectations Versus Facts on the Implementation of Adolescent Care Health Service
}

\author{
Muthmainnah $^{1}$, Ira Nurmala ${ }^{1}$, Pulung Siswantara ${ }^{1}$, Riris Diana $\mathbf{R}^{1}$, Eka Yeyen $\mathbf{P}^{1}$ \\ ${ }^{1}$ Department of Health Promotion and Behavior Sciences, Faculty of Public Health Universitas Airlangga
}

\begin{abstract}
Percentage of adolescents in Indonesia nearly reaches $30 \%$ of the total population. This amount is relatively huge and able to be the nation's asset, if it is managed properly. Various adolescent reproductive health programs have been conducted in diverse sectors - governmental or even non-governmental. One of which is called the Adolescent Care Health Service (ACHS). This research aims to identify adolescent expectations and facts on ACHS program implementation. Research methods were used mixed methods. Quantitative data were collected from 842 respondents (high school students in Surabaya, Indonesia) from questionnaires, while qualitative data were collected from interviews with quantitative respondents at the same time using purposive random sampling. Data analysis was also conducted with the mixed methods using quantitative and qualitative descriptive, based on the data and information collected. Research results showed that $76.2 \%$ did not know the existence of ACHS program and 90\% had never accessed the program. Qualitative data implied that adolescent hoped for an adolescent health program which fitted adolescents' characteristics, needs and capacities; for instance, one which utilized entertaining method and media. However, in fact, the method and media used had a patronizing tendency and based on the informants were very boring and moreover, the adolescents' involvement in the program planning was only $8.4 \%$. According to the ACHS implementaion national standard, adolescents need to be involved starting from planning to evaluation of the program. In addition to that, the ACHS program is supposed to be adolescent-friendly—fit the adolescent needs.
\end{abstract}

Keywords: Expectations, Facts, Implementation, Program, ACHS.

\section{Introduction}

Adolescents according to $\mathrm{WHO}$ are those at the age of 10-19 years old and demographically divided into two age groups; for 10-15 and 15-19 years old. Based on the data of Indonesia Population Projection 2000-2025, proportion of 10-19 years old adolescent population in 2010 is approximately $18.3 \%$ from the total population, or about 43 millions. The amount of adolescent age group populations may be interpreted as the nations's future asset and potential. However, in order to fulfill these expectations, the nation and the society must be able to assure that Indonesian adolescents can grow and develop positively, and are free from various threatening problems. ${ }^{1}$

\section{Corresponding Author:}

Muthmainnah

Department of Health Promotion and Behavior Sciences, Faculty of Public Health Universitas Airlangga

Email: muthmainnah@fkm.unair.ac.id
Care for adolescents' problems in Indonesia has been fostered, although it still has many shortcomings. Strategy to conduct the adolescent health policy is carried by the government through cross-sectional cooperation, fundamental health service and its referral, and intervention pattern. This strategy undoubtedly has been adjusted to the needs of adolescent growth and development. $^{2}$ Since 2003, the Health Ministry has developed a adolescent health program with a specialized approach known as Adolescent Care Health Service (ACHS). Adolescent Care Health Service (ACHS) is a model of health care for adolescents in primary health care services. ACHS is a policy to improve the adolescents' health. This approach aims to encourage providers, particularly Public Health Centres, to be able to give health services which are comprehensive, compatible and fulfilling to the needs of adolescents who hope for privacy, recognition, value and involvement; in planning, execution, to evaluation of the program.

In 2014, a national standard guidebook was prepared as a reference in the implementation of ACHS, 